\title{
Combined effects of particulates dispersion and elemental analysis in desert plants: a modeling tool to air pollution
}

\author{
A. H. Bu-Olayan ${ }^{1}$ - B. V. Thomas ${ }^{1}$
}

Received: 30 June 2015/Revised: 29 December 2015/Accepted: 18 February 2016/Published online: 7 March 2016

(C) Islamic Azad University (IAU) 2016

\begin{abstract}
Multidimensional assessment of air pollution was carried out on trace metals in particulates, desert plant parts and soil collected from the six sites to validate air pollution tolerance index, translocation and bioaccumulation factors. A map indicating the sampled sites was superimposed on the Disper 5.2 software graphical interface to track the particulate dispersion route during the summer and winter seasons. This study showed site-wise orientation of particulates dispersed in the ambient air. Observations indicated the high concentrations of dispersed coarse $>$ fine $>$ ultra-fine particulates in trace metals analyzed from selected desert plants and in the soil especially during winter than in the summer seasons. High air pollution tolerance index was observed in the sequence of Calatropis gigantean $>$ Portulaca oleracea $>$ Citrullus collocynthis $>$ Rumex vesicarius $>$ Bienertia sinuspersici $>$ Tribulus terrestris. Assessment of translocation and bioaccumulation factors labeled these desert plants as hyper-accumulators. The synergistic effect of the translocation and bioaccumulation factor in the various plants and the pollution levels for a given geographical location provides insight management to mitigate air pollution and landscape designers to grow tolerant species and protect sensitive plants from air pollution.
\end{abstract}

Electronic supplementary material The online version of this article (doi:10.1007/s13762-016-0968-5) contains supplementary material, which is available to authorized users.

\section{B. V. Thomas}

drbivin.thomas@ku.edu.kw

1 Department of Chemistry, Kuwait University, Khaldiya Campus, POB 5969, 13060 Safat, Kuwait
Keywords Pollution indices · Soil · Trace metals · Wild flora

\section{Introduction}

The primary producer, an integral source for all ecosystems, is susceptible to airborne pollution. The main parts of these producers are their leaves. They are the most abundant and primary receptors of air pollutants. Ninave et al. (2001), Fismes et al. (2002), Liu and Ding (2008) and Jyothi and Jaya (2010) assessed the concentrations of inorganic and organic constituents in the plant parts and correlated the absorption of pollutants from air, soil, water and anthropogenic sources. Ukpebor et al. (2010) labeled plants as active or passive bio-monitors based on the trace metal deposition from such sources. Plants tend to sequester trace metals through the shoot and roots. Conti et al. (2004) observed variations of trace metal accumulation in plants because of age, health status, the availability of trace metals, types of reproduction, temperature, moisture and substratum characteristics. Their concentrations were correlated with the surrounding soil. Trace metals were found to absorb by plants from the air and sequester to secondary consumers. Virtually, a uniform distribution of trace metal transfer was observed in the arid ecosystem during dust storm or owing to the influence of heavy wind action (Wang et al. 2004; Youn-Joo 2004; Reinier et al. 2011). Yoon et al. (2006), Yu-Hong et al. (2010), Cyren et al. (2011) and Takanori and Naoko (2012) quantified the concentrations of pollutants in the different plant parts and determined the translocation (TF) and bio-accumulation factors. Baker and Brooks (1989) classified $\mathrm{TF}<1$, $\mathrm{TF}=1$ and $\mathrm{TF}>1$ as plants with 'least,' 'moderate' and 'effective' translocation factors, respectively. Ma et al. 
(2001) labeled plants with bioaccumulation factor $\mathrm{BAF}>1, \mathrm{BAF}=1$ and $\mathrm{BAF}<1$ as hyper-accumulators, accumulator and trace metals excluder, respectively. Dohmen et al. (1990) revealed the physiological changes in plants exposed to air pollutants before exhibiting visible damages to plant leaves. Joshi and Swami (2007), Cheng et al. (2007) and Seyyednejad et al. (2011) validated the tolerance levels of the plant species using the air pollution tolerance index (APTI). Seyyednejad and Koochak (2013) categorized plants with APTI $<10,>10$ and $>17$ as sensitive, tolerant and highly tolerant species to particulate matter. These studies indicated the stress on plants due to the particulate deposition from the ambient atmosphere. Kuwait's geography is discerned by high windswept sand and dust, long, hot and dry summer, short and cold and winter with the scanty rain sometimes (Brown et al. 2008). Investigators (Pasquill 1976; Keane et al. 2001; Bader AlAzmi et al. 2008; Reem et al. 2010) observed low photosynthetic activities and productivity of plants due to the frequent sand storms that dispersed coarse $\left(\mathrm{PM}_{10}\right)$, fine $\left(\mathrm{PM}_{2.5}\right)$ and ultra-fine particulates $\left(\mathrm{PM}_{1.0}\right)$ containing organic and inorganic pollutants, in addition to the dispersal of particulates from the oil industries and automobile emissions. Several studies in the past showed the effect of elemental concentrations in certain shrubs and trees (Brown et al. 2008; Reem et al. 2010; Bu-Olayan and Thomas 2014). However, no evidences indicated the effect of particulate trajectories and their elemental constituent that deposited and absorbed by the desert plants. Furthermore, the effect of trace metals on selected ornamental and medicinal plants of importance, such as Portulaca oleracea, Citrullus colocynthis, Rumex vesicarius, Bienertia sinuspersici, Tribulus terrestris and Calatropis gigantean, was not investigated and hence the study. The dispersion route and the determination of trace metals in particulates from the ambient atmosphere serve as a potential tool to quantify the magnitude and distance of particulates dispersed for a given locality besides their role in abiotic and biotic components. This study also deduced the dependent factors of pollutant dispersion following the observations of Pasquill (1976), Briggs (1979), Press et al. (1986) such as meteorological variables (weather parameters, mixing height of pollutant dispersion), atmospheric turbulence characteristics (Pasquill stability, $K$ values), intensity of wind insolation during the day and night times), area source data (pollution emission rate, decay coefficient) and seasonal variations (summer and winter). The present study conducted during the years 2012-2014 with multidimensional approach focused: (a) the use of DISPER numerical simulation program (version 5.2: Canarina Environmental Software, Spain) to trace size-cut particulate $\left(\mathrm{PM}_{10}, \mathrm{PM}_{2.5}\right.$, $\mathrm{PM}_{1.0}$ ) trajectories, (b) the physiological stress to selected desert plants encompassing the six Kuwait Governorate sites using air pollution tolerance index (APTI), (c) translocation (TF) and the bioaccumulation factors (BAF) of trace metals in the desert plants, (d) to correlate the seasonal variations of trace metals concentrations in plants and in the soil and (e) to deduce the appropriate plants that could be used for mitigation purposes.

\section{Materials and methods}

\section{Sampling sites}

Six sites in Kuwait were chosen for the study (G1-G6: Fig. 1a). These sites (G1-G6) house occupational diversity such as industries, agricultural farms, populated residential areas, desalination plants, commercial and recreational centers, oil fields and oil wells. Southeast of the G1 adjacent to G4 and G2 and southeast of G6 along the coastal side are also heavily polluted. Sites G2 to G5 and the northern part of the site G6 is densely populated, whereas the northern part of site G1 and the southern part of the site G6 are sparingly populated.

\section{Meteorological data}

Meteorological data such as temperature, wind speed, relative humidity and barometric pressure were recorded using Kestrel-4500 (Nielsen-Kellerman, USA) during the onset, peak and late summer (April-July-October) and winter (November-January-March) seasons, respectively.

\section{Sample collection}

An environmental particulate air monitoring system, EPAM-5000 (Haz Dust, USA) with nephelometric and gravimetric principles, measured the concentrations of the ambient atmospheric particulates $\left(\mathrm{PM}_{10}, \mathrm{PM}_{2.5}\right.$ and $\left.\mathrm{PM}_{1.0}\right)$ from each site and surrounding the sampled desert plants. Three sampling sleeves, each to collect particulate sizes $\left(\mathrm{PM}_{10}, \mathrm{PM}_{2.5}, \mathrm{PM}_{1.0}\right)$, were consecutively fixed on a sampling head of the EPAM-5000 instrument, while sampling each site for assessing the real-time spatially dispersed particulate concentrations by nephelometric principles designed in this instrument. This instrument simultaneously measured the real-time spatially distributed and trapped particulates by impact filter (47mmFRM, Whatman, USA) from the sampling sites. The filters containing the particulates from each site were separately stored in sterile polystyrene bags for trace metals analysis.

During the years 2012-2014, desert plant parts (7776 numbers: six sites $\times$ six desert plants species $\times$ three parts-leaf, stem, root $\times$ three replicates each, for two times/month sampling in two seasons @ 3 months/ 

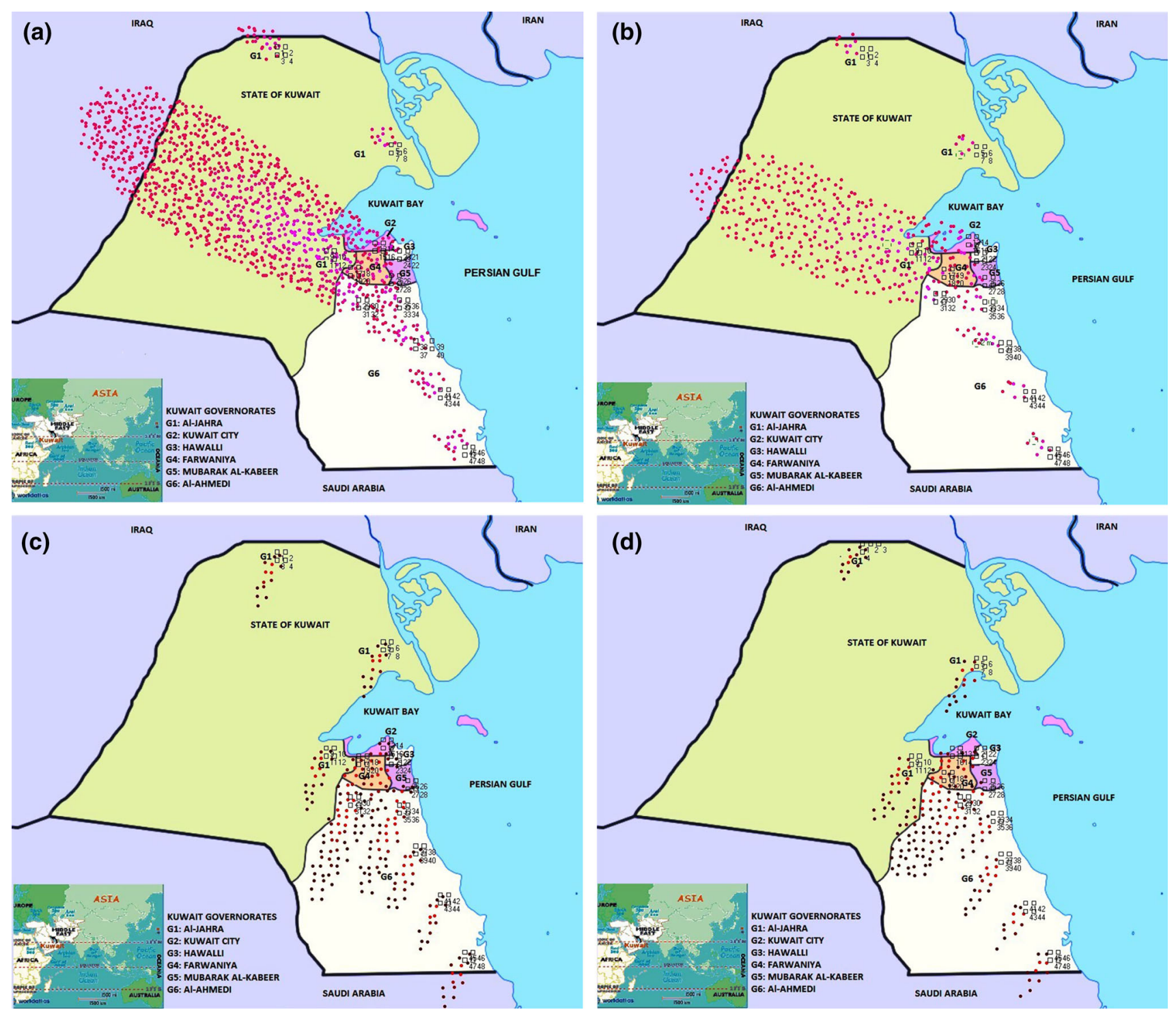

Fig. 1 a Particulate dispersion and sampling sites of desert plants in Kuwait during summer $\left(42^{\circ} \mathrm{C}\right)$. b Particulate dispersion and sampling sites of desert plants in Kuwait during summer $\left(48^{\circ} \mathrm{C}\right)$. c Particulate

season $\times 2$ years) were collected (Fig. 1a) in sterile polyethylene labeled zipper bags $(34 \mathrm{~cm} \times 30 \mathrm{~cm} \times 0.3 \mathrm{~mm}$ Fisher brand, USA). Species, namely Tribulus terrestris L., Rumex vesicarius L., Portulaca oleracea L., Citrullus colocynthis L., Bienertia sinuspersici L. and Calatropis gigantea $\mathrm{L}$., were collected in a sterile bag, stored in a Thermo Cole box and transported to the laboratory. These plants were found to be of medicinal importance except the halophyte, B. sinuspersici $\mathrm{L}$. These plants were observed to be on the verge of extinction because of urbanization and rapid industrialization and hence the study.

Following the earlier methods (Keane et al. 2001; Agbaire 2009; Abida and Harikrishna 2010), the surface dust on the selected desert plant parts (ten replicates) was

dispersion and sampling sites of desert plants in Kuwait during winter $\left(5{ }^{\circ} \mathrm{C}\right)$. d Particulate dispersion and sampling sites of desert plants in Kuwait during winter $\left(15^{\circ} \mathrm{C}\right)$

removed by rinsing it in deionized distilled water. Fresh plant leaves from each species was used to assess the chlorophyll content, relative water content, $\mathrm{pH}$ of leaf extract, ascorbic acid content and air pollution tolerance index (APTI). In sterile petri dishes, replicate samples of leaves, stem and roots from each species were cut into pieces and stored at $-4{ }^{\circ} \mathrm{C}$ in the deep freezer and thawed at room temperature for trace metals analysis (USEPA 1999; Abida and Harikrishna 2010).

Using a soil auger, $\left(15^{\prime \prime} \mathrm{L} \times 3-1 / 4^{\prime \prime}\right.$ diameter, AMS, Inc.), soil samples (3456 numbers: $50 \mathrm{~g}$ each) at $0.1 \mathrm{~m}$ depth from the surface at four equidistant points $(10-15 \mathrm{~cm})$ and away from the center of each surrounding desert plant (four points/plant $\times$ six plants/site $\times$ six 
sites $\times$ two times/month @ 3 months/season in two seasons $\times 2$ years) were collected, sieved in $1.0-\mathrm{mm}$ mesh sieve and stored in sterile polyethylene containers following the earlier methodology (Zhuang et al. 2007).

\section{Numerical simulation of particulates emission}

The map of Kuwait indicating the sampling locations (Fig. 1a-d) was superimposed with the corresponding coordinates present in the graphical interface of the DISPER-5.2 program. This program incorporated meteorological variables, concentrations of particulates and the characteristic features of the sampling location that was recorded by Kestrel-4500, EPAM-5000 and ICP-MS instruments besides the physical measurements of the sampled sites to obtain the direction and intensity of particulates dispersed in the ambient environment.

DISPER-5.2 program (Canaria, Spain) software with graphical user interface creates robust numerical simulations. A combination of Gaussian Plume, Briggs stability, decay coefficient and algorithm dispersion model (Pasquill 1976; Briggs 1979; Press et al. 1986; USEPA 1999) was used to study the determinants of nonpoint sources that simulated the effects of fugitive emissions and represented by small and many intervals from which the total particulate concentrations were calculated.

\section{Chlorophyll pigment extraction}

The desert plant's leaves were washed in deionized distilled water and cut into small pieces. Following the earlier method (Abida and Harikrishna 2010), fresh desert plant leaves at random from each species $(100 \mathrm{mg})$ was homogenized and the chlorophyll pigment was measured in the UV-visible spectrophotometer (Milton Roy Spectronic
20D, USA). Absorbance was read at 645 and $663 \mathrm{~nm}$ for chlorophyll $\mathrm{b}_{\mathrm{b}}$ and chlorophyll $\mathrm{a}$, respectively. The absorption coefficient concentrations of chlorophyll were calculated using the following equations (Abida and Harikrishna 2010):

$$
\begin{aligned}
& \mathrm{Chl}_{\mathrm{a}}(\mathrm{mg} / \mathrm{g})=22.7 \times \mathrm{OD}_{663}-2.69 \times \mathrm{OD}_{645} \\
& \mathrm{Chl}_{\mathrm{b}}(\mathrm{mg} / \mathrm{g})=12.9 \times \mathrm{OD}_{645}-4.68 \times \mathrm{OD}_{663}
\end{aligned}
$$

Total Chlorophyll $=\mathrm{Chl}_{\mathrm{a}}+\mathrm{Ch}_{\mathrm{b}} \mathrm{mg} / \mathrm{g}$

\section{Relative water content (RWC)}

Initially, the fresh weight of the desert plant leaves from each species was recorded. The leaves were immersed in water overnight, blotted dry the next day and turgid weight obtained. The leaves were dried in an oven at $70{ }^{\circ} \mathrm{C}$, and the dry weight recorded (Rahimi et al. 2010).

\section{pH of leaf extract}

Leaves $(5 \mathrm{~g})$ were homogenized in $50 \mathrm{ml}$ deionized water and filtered. The $\mathrm{pH}$ of the extract was recorded using a bench top $\mathrm{pH}$ meter (Mettler Toledo).

\section{Ascorbic acid content (AA) and air pollution tolerance index (APTI)}

Fresh leaves $(1 \mathrm{~g})$ from each sample were treated with oxalic acid-EDTA, orthophosphoric acid, sulfuric acid, ammonium molybdate and deionized water (Smirnoff 1996). The solution was left undisturbed, and the absorption observed at $760 \mathrm{~nm}$ using a spectrophotometer (Yoon et al. 2006). Using the following equation, air pollution tolerance index (APTI) was calculated:

$\mathrm{APTI}=[\mathrm{AA}(T+P)+R] / 10$
Fig. 2 Meteorological variables in the six Sites. $A V$ air velocity, $B P$ barometric pressure, $A F$ air flow, $A L$ altitude, $R H$ relative humidity, $T P$ temperature, G1-G6 Governorate sites, $S$ summer, $W$ winter

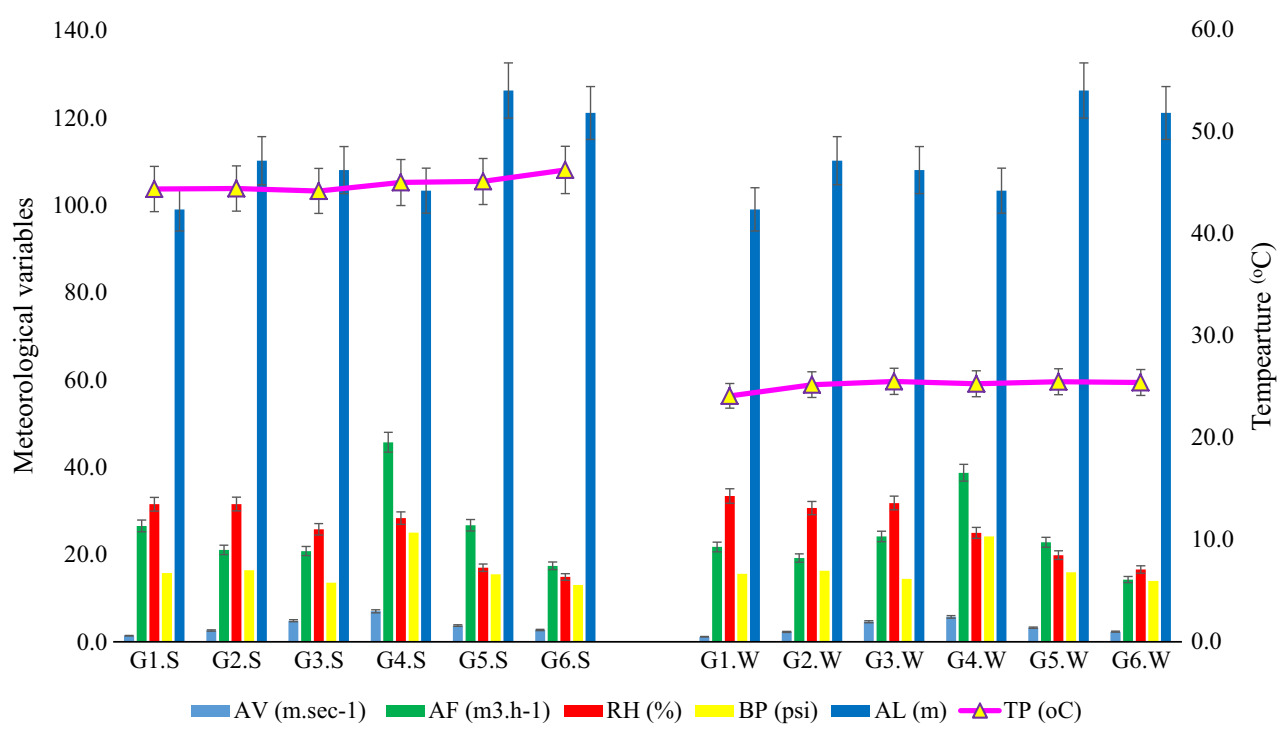


wherein AA $=$ ascorbic acid $\left(\mathrm{mg} \mathrm{g}^{-1}\right), T=$ total chlorophyll $\left(\mathrm{mg} \mathrm{g}^{-1}\right), P=\mathrm{pH}$ of leaf sample, $R=$ relative water content $\left(\mathrm{mg} \mathrm{g}^{-1}\right)$. Agbaire (2009) classified plants into three groups based on their APTI values, namely (a) sensitive species (APTI $<10$ ), (b) intermediate tolerant species (APTI 10-16) and (c) highly tolerant species (APTI > 17).

\section{Trace metals in particulates, desert plant species} and soil

Particulates $\left(\mathrm{PM}_{10}\right.$ to $\left.\mathrm{PM}_{1.0}\right)$ sample filters, plant parts (root, stem, leaves: $0.2 \mathrm{~g}$ each) and soil samples $(0.2 \mathrm{~g})$ were predigested with 5,6 and $8 \%$ nitric acid $(\mathrm{v} / \mathrm{v})$ in a sterile polystyrene centrifuge tube $(50 \mathrm{ml}$ capacity) overnight to pre-concentrate the trace metals, respectively
Fig. 3 Site-wise analysis of trace metals in particulates, desert plants, soil versus particulate dispersion. $W$ winter, $S$ summer, $t m$ trace metals, $D p$ desert plants, $D$ dispersed particulates, PM10, PM2.5, PM1.0: particulate sizes

$$
25.0
$$

250.0

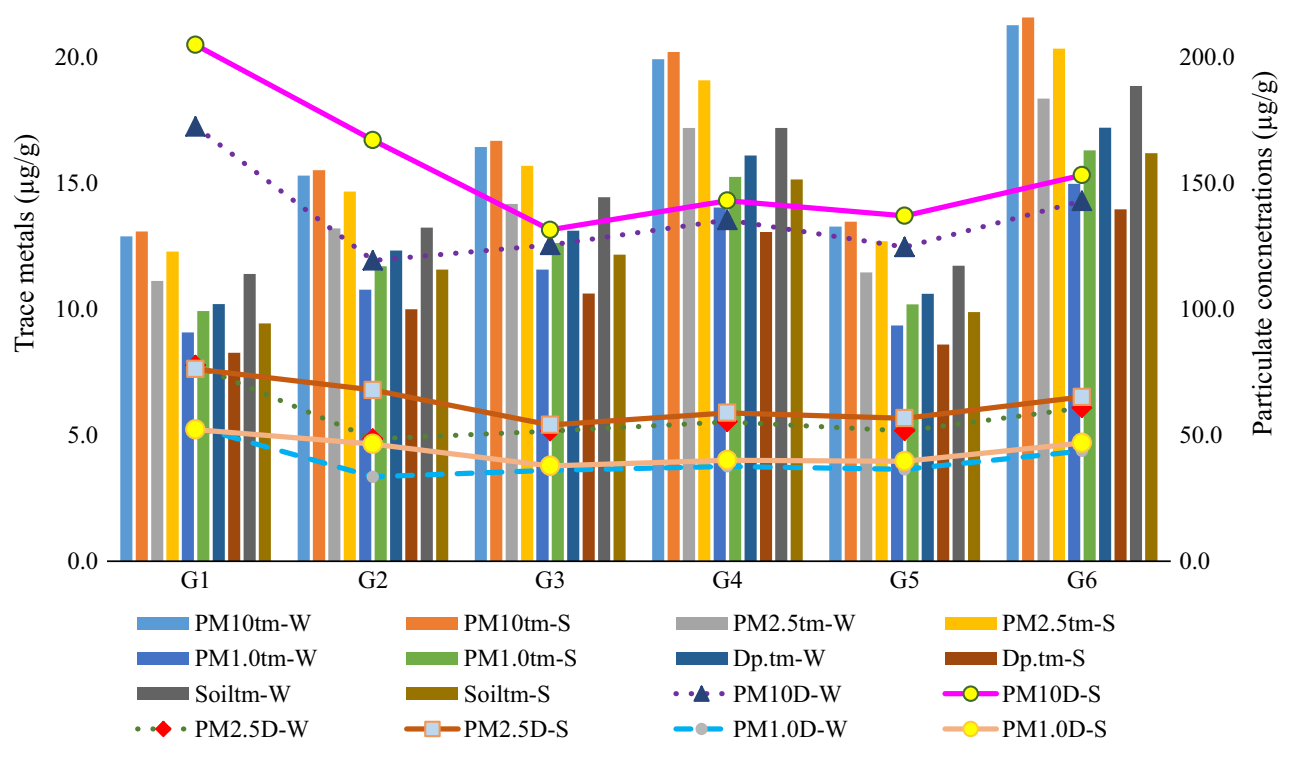

Fig. 4 Metals-wise analysis in particulates, desert plants and soil. $W$ winter, $S$ summer, $t m$ trace metals, $D$ desert plants
70.0

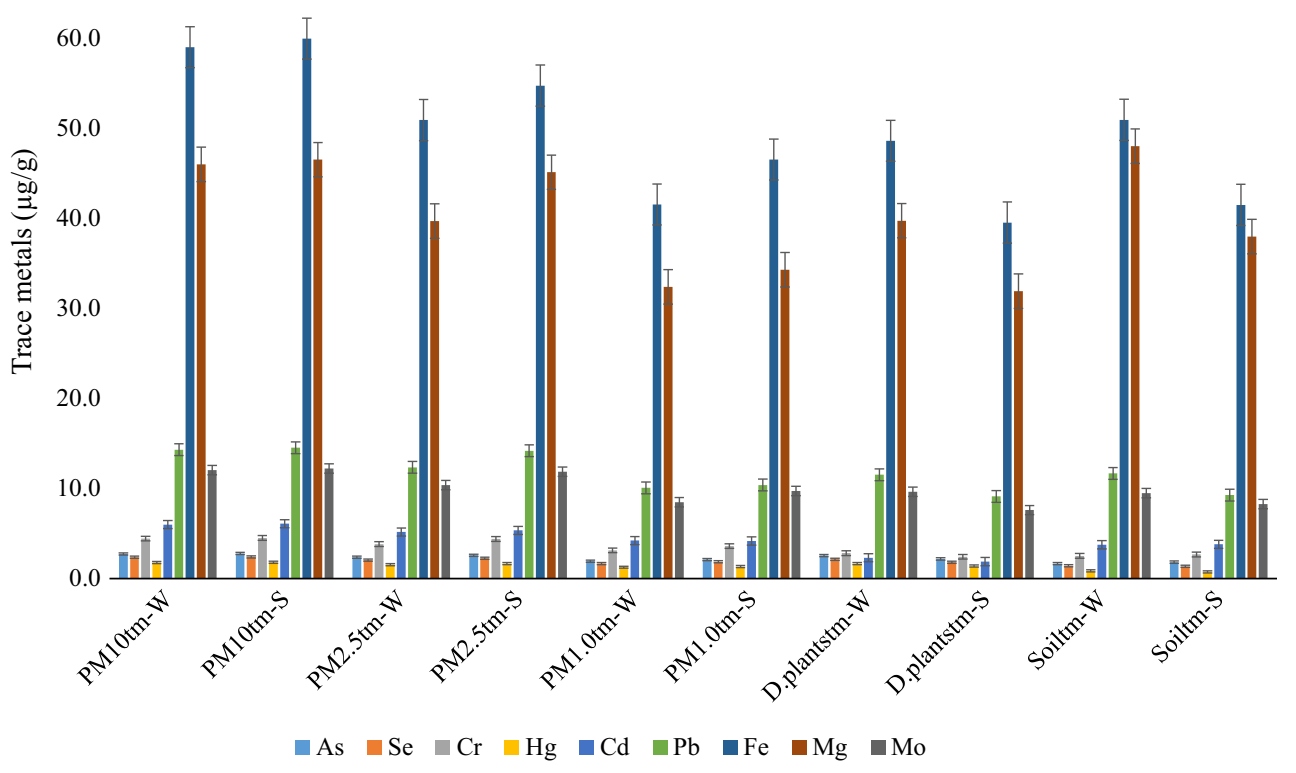


(Seyyednejad and Koochak 2013). The soil samples were completely predigested by adding $1 \mathrm{ml}$ of hydrofluoric acid $(\mathrm{v} / \mathrm{v})$ in addition to $8 \%$ of concentrated nitric acid overnight. Individually, samples were digested in an automatic microwave digester (Ethos 1, Milestone, Italy, Inc) and diluted with deionized distilled water. The digested sample was measured for trace metals in the ICP-MS. Quality assurance was followed using appropriate blanks, replicates and ICP-MS standards to test the precision of the instrument, repeatability and reproducibility of the analysis. Samples that showed $>98 \%$ recovery of trace metals concentrations in particulates, desert plants and soil with that of the urban particulate dust (SRM1648a), orchard leaves (SRM-1571) and Montana soil (SRM-2711 from NIST, USA), respectively, from National Institute of Standard Technology (NIST, USA) were alone considered for data analysis. Samples were also statistically validated using SPSS-19 software to validate the hypothesis and significance of the results.

\section{Translocation (TF) and bioaccumulation (BAF) factors in the desert plant species}

Trace metals translocation (TF) in the selected desert plants from root to shoot was calculated using the following equation:

$\mathrm{TF}=C_{\mathrm{st}} / C_{\mathrm{rt}}$

wherein ' $C_{\mathrm{st}}$ and $C_{\mathrm{rt}}$ ' are the metal concentrations ( $\mu \mathrm{g} \mathrm{g}^{-1}$ ) in the shoot and root, respectively. Calculations that showed $\mathrm{TF}<1, \mathrm{TF}=1$ and $\mathrm{TF}>1$ were classified as plants with 'low translocation,' 'moderate translocation' and 'effective translocation,' from the root to the shoot of any given plant, respectively (Baker and Brooks 1989). Likewise, Ma et al. (2001) classification of trace metals bioaccumulation factor, namely $\mathrm{BAF}>1, \mathrm{BAF}=1$ and $\mathrm{BAF}<1$ as hyper-accumulators, accumulator and excluder of trace metals, respectively, in these plants was used to calculate the ratio of trace metals concentration in the aerial parts of the plants to that of the soil.

\section{Results and discussion}

Site-wise observations (Fig. 1a-d) revealed an evenly distributed pattern of trace metals in particulates within a given season, but showed variations between the winter and summer seasons (Fig. 2). This was due to the low barometric pressure, altitude and wind action in this region besides the influence of emissions from small-scale industries. Particulate dispersion in G4 site was observed high with increasing air flow and air velocity when compared with the dispersion in the other sampled sites. Reasons attributed to the wind direction, influence of open sites of G6 causing particulate dispersion in the G4 sites besides the influence of human activities. This phenomenon was in contrary to the other sites as well as to that of the earlier studies of Zhuang et al. (2007), Reem et al. (2010) wherein they noticed high particulate dispersion in areas with moderate air velocity. High dispersion of particulates in ambient air was observed in the sequence of $\mathrm{PM}_{10}>-$ $\mathrm{PM}_{2.5}>\mathrm{PM}_{1.0}$ irrespective of the sampled sites and the
Fig. 5 Seasonal-wise air pollution tolerance index (APTI) of the selected desert plants of Kuwait. $W$ winter, $S$ summer, $T$ - $C H L$ total chlorophyll, $R W C$ relative water content, $A A$ ascorbic acid, $A P T I$ air pollution tolerance index

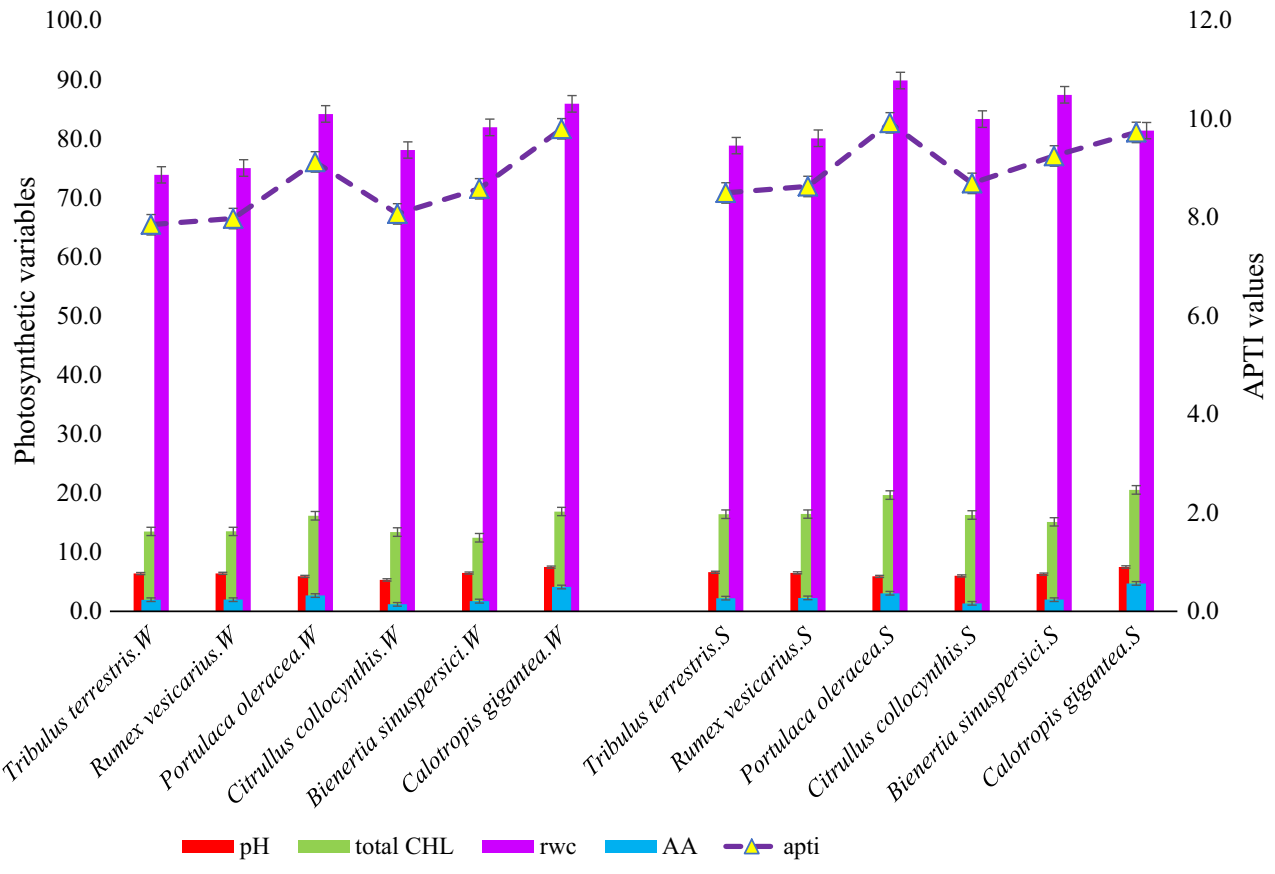


two seasons (Fig. 3). High trace metals concentrations in G6 and G4 attributed to the influence of air pollutants from the oil wells, industries and human activities in comparison with pollutant levels from the other sites. Earlier studies (Reem et al. 2010; Rahimi et al. 2010; Seyyednejad and Koochak 2013) showed such observations with organic constituents. Seasonal-wise analysis revealed high particulate dispersion during summer than in winter. This was due to the influence of frequent dust storm causing high particulate dispersion during summer. The reverse phenomenon was observed in the case of trace metal composition during winter due to the effect of precipitate that makes the particulates dense and combines with other organic compounds causing the rise in elemental composition (Fig. 4).

The multidimensional approach of air pollution was validated by determining the chemical constituency in plants using suitable index. The total chlorophyll content
Fig. 6 Species-wise trace metals concentrations in selected desert plants. $W$ winter, $S$ summer

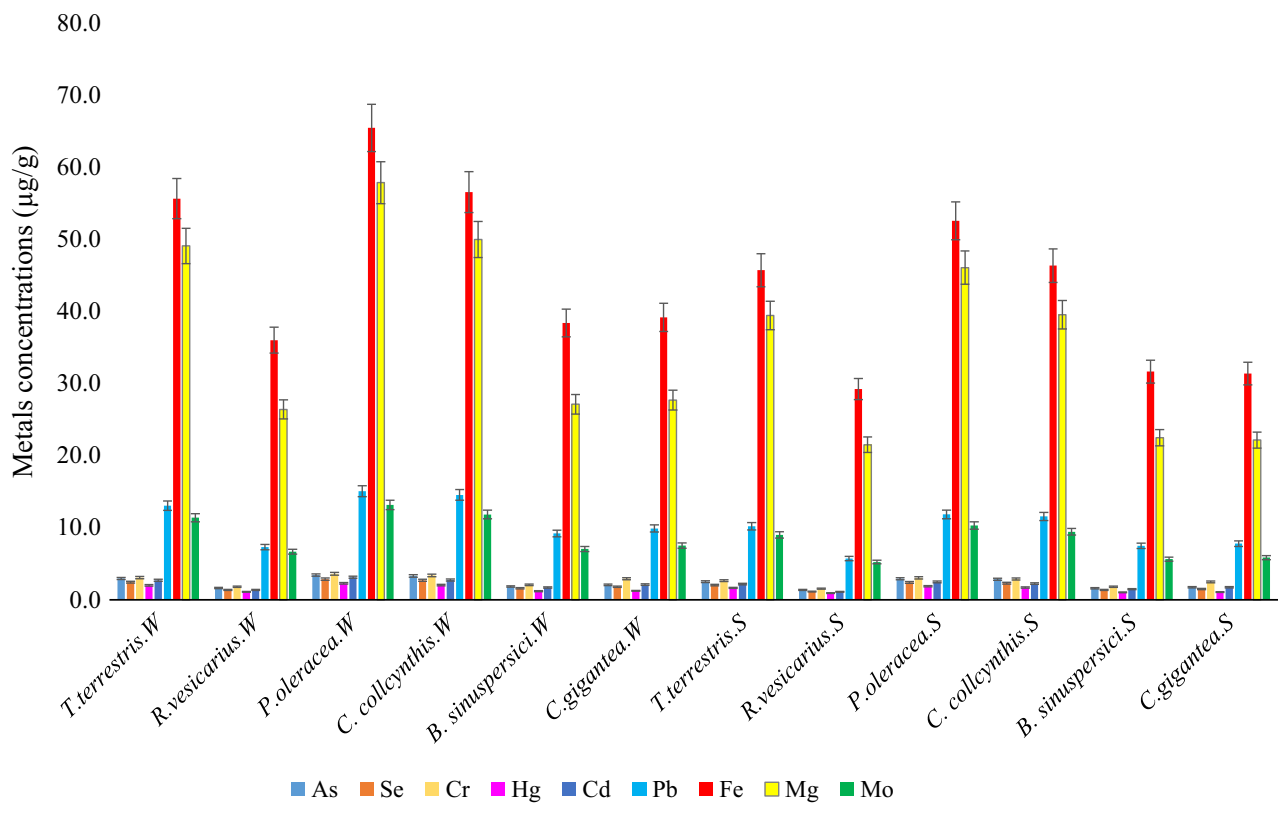

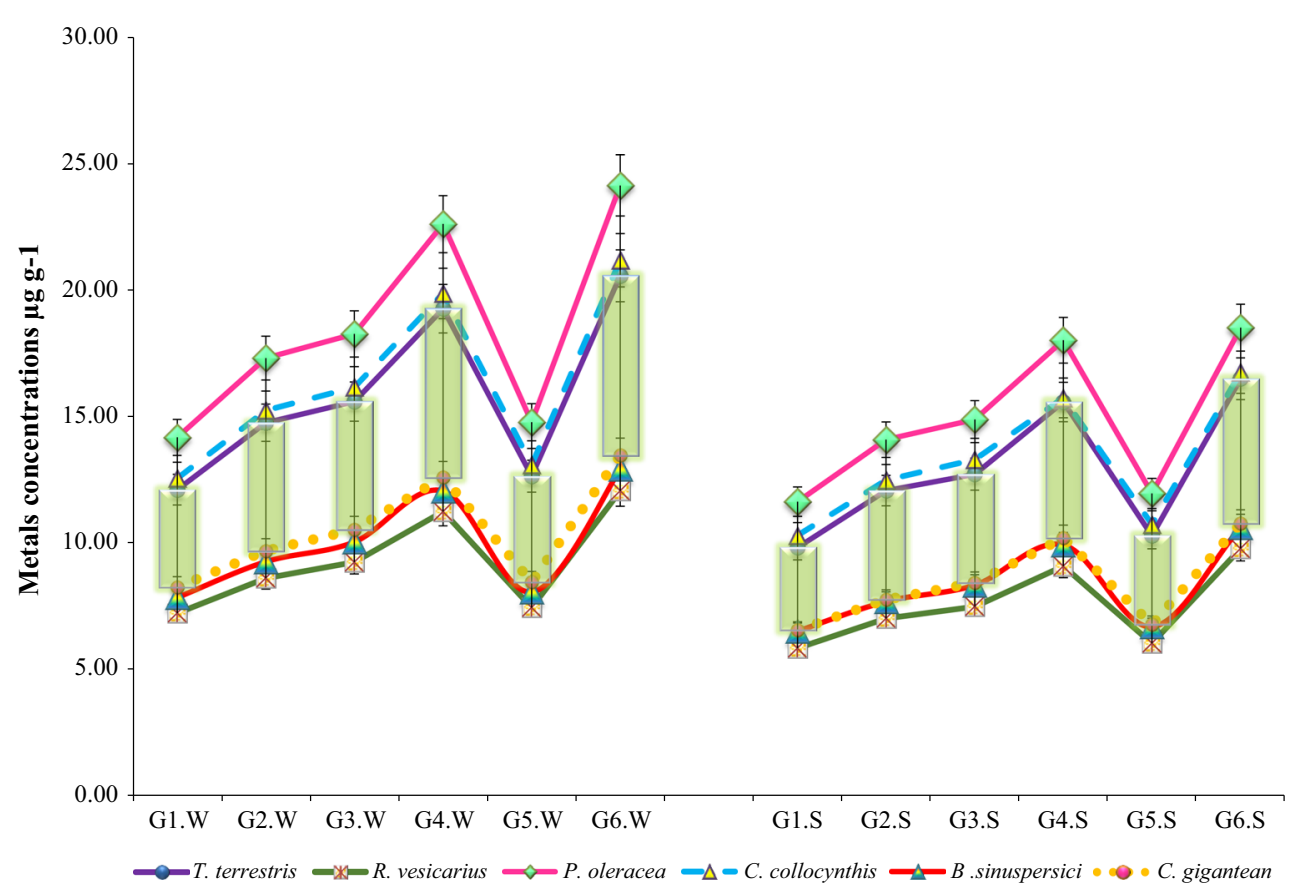

Fig. 7 Site-wise trace metals concentrations in the six selected desert plants of Kuwait. G1-G6 Governorate sites, $W$ winter, $S$ summer 
was high in the sequence of Rumex vesicarius $>$ Portulaca oleracea $>$ Bienertia sinuspersici $>$ Calatropis gigantean $>$ Citrullus collocynthis $>$ Tribulus terrestris leaves among the six selected desert plants irrespective of the area-wise and seasonal-wise variations (Fig. 5). Low chlorophyll content in the leaves of Tribulus terrestris attributes to the low number of chloroplast cell distribution and minimal surface area when compared to the other plants. The reverse characteristic features were noticed in $R$. vesicarius and hence the high chlorophyll content in such plants.

The relative water content was high in $P$. oleracea and C. collocynthis followed by the other desert plants (Fig. 5). The high relative content in the leaves of these desert plants attributes to the water absorption capabilities of the soil and the extent of stomata constraints stresses in the desert ecosystem. This was found in line with the earlier studies (Ninave et al. 2001; Smirnoff 1996; Seyyednejad and Koochak 2013).

$\mathrm{pH}$ ranged between 5.85 and 8.15 among the sampled plants. Comparatively, $\mathrm{pH}$ was higher in $C$. gigantean and $P$. oleracea than the other species (Fig. 5). Among the six selected desert plants, high ascorbic acid content was observed in $C$. gigantean than the other species. High ascorbic acid content in $C$. gigantean labeled this plant as intermediary tolerant and sensitive species to air pollutants. Innumerable leaves on these plants and the influence of photosynthetic activity were found to increase the ascorbic acid concentrations in their chloroplasts, thus supporting the earlier views (Liu and Ding 2008; Jyothi and Jaya 2010; Cheng et al. 2007; Cyren et al. 2011).

Observation revealed high air pollution tolerance index (APTI) in the sequence of $C$. gigantean $>P$. oleracea $>C$. collocynthis $>R$. vesicarius $>B$. sinuspersici $>T$. terrestris (Fig. 5). APTI $>10$ in $C$. gigantean indicated the high tolerance to air pollution. This was probably due to the interaction of biochemical parameters in their aerial parts when compared to the APTI values in the other sampled desert plants and irrespective of site specificity. This suggests that $C$. gigantean could be used to ameliorate air pollution. Except $C$. gigantean, the APTI $<10$ in the five selected desert plants indicated their sensitivity to air pollution. Similar results were observed by earlier investigators (Smirnoff 1996; Joshi and Swami 2007; Rahimi et al. 2010). In the present study, the influence of environmental variables (high wind velocity, high temperature and low humidity), and frequent dust storms, besides the effect of precipitation, was validated by high ATPI in winter than in the summer seasons.

In an overall view, trace metals concentrations were found higher in the six desert plant parts during the winter than in the summer season (Fig. 6). This could be attributed to the low photosynthetic activities when compared to their activities during the summer season. Species-wise analysis revealed high metal concentrations in $P$. oleracea $>C$. collocynthis $>T$. terrestris $>C$. gigantean $>B$. sinuspersici $>R$. vesicarius. Desert plants, $P$. oleracea and $C$. collocynthis, indicated varying absorption
Fig. 8 Translocation and bioaccumulation factor in the selected desert plants. $W$ winter, $S$ summer, $T F$ translocation factor (shoot/root), $B A F$ bioaccumulation factor (plant parts/soil), $A G L$ aerial parts/soil, BGL: root/soil

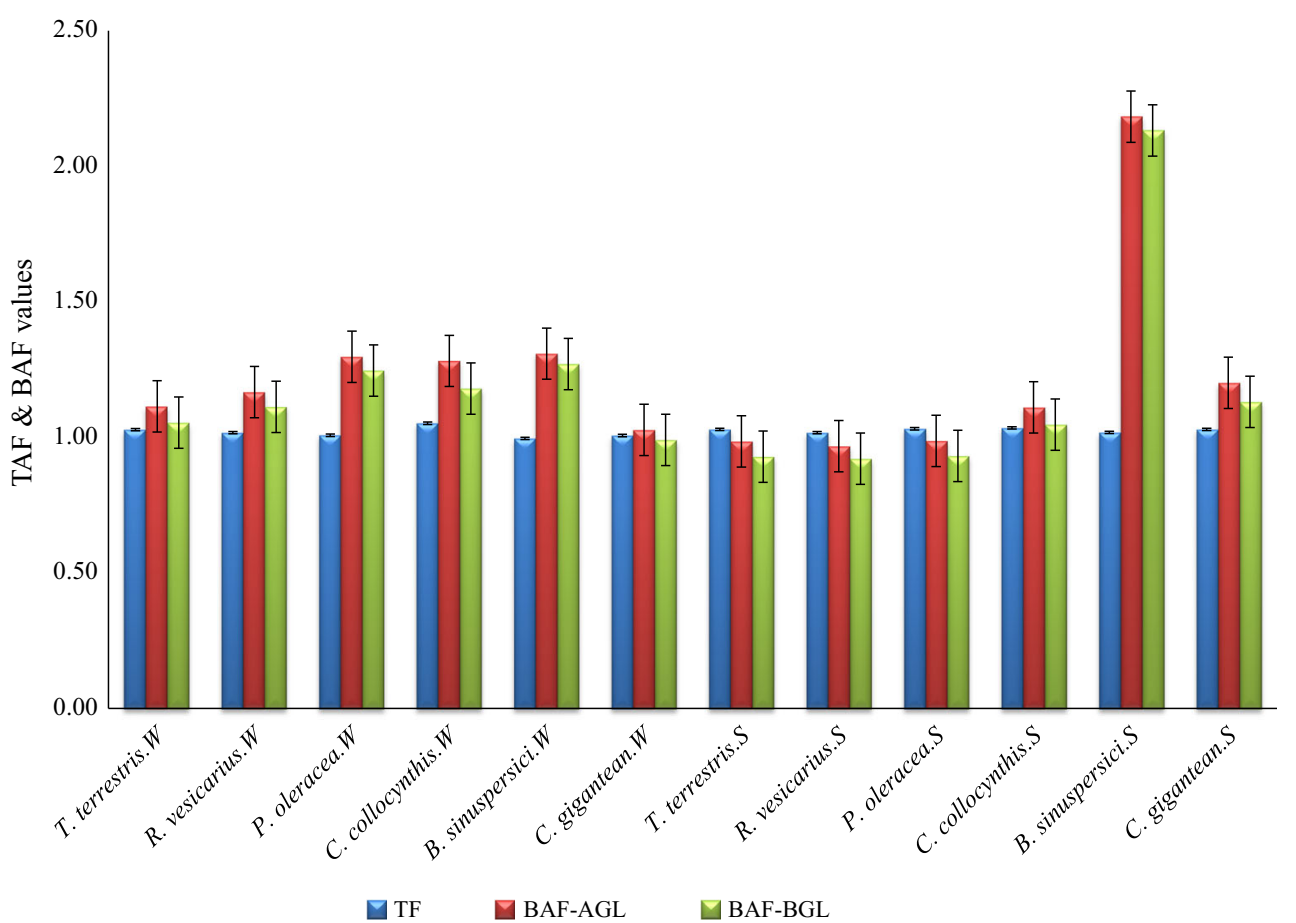


capabilities of trace metals from the surrounding air, particulates, dust, water and soil and hence the high metals concentrations. Similar findings with other plants were reported by Wang et al. (2004), Youn-Joo (2004), Abida and Harikrishna (2010), Cyren et al. (2011) and Bu-Olayan and Thomas (2014). High trace metals concentrations in these plants were noted in the sequence of $\mathrm{Fe}>\mathrm{Mg}>\mathrm{Pb}>\mathrm{Mo}>\mathrm{Cr}>\mathrm{As}>\mathrm{Cd}>\mathrm{Se}>\mathrm{Hg}$ in G6 $>\mathrm{G} 4>\mathrm{G} 3>\mathrm{G} 2>\mathrm{G} 5>\mathrm{G} 1$, respectively (Figs. 6, 7). The influence of oil pollution, automobile emission and high commercial activities was found to cause such high metals concentrations in the six desert plants. This sequence of high trace metals concentrations was observed by Fismes et al. (2002), Ma et al. (2001), Keane et al. (2001) and Jyothi and Jaya (2010) but with different plants, thus indicating the necessity of trace metals pollution remediation in sites of divergent human activities.

Trace metals concentrations in the soil were higher in the sites $\mathrm{G} 6>\mathrm{G} 4>\mathrm{G} 3>\mathrm{G} 2>\mathrm{G} 5>\mathrm{G} 1$ during winter than in the summer (Figs. 3, 4). Reasons may be attributed to the soil characteristics, anthropogenic sources and meteorological variables interaction. Plants that absorbed trace metals from the soil sites, G6 and G4, are attributed to the impact of the high trace metals concentrations from such sources. Furthermore, the analysis of trace metals concentrations in soil led to quantify the metals, transportation ratio in the selected plants using translocation (TF) and bioaccumulation factors (BAF). TF was $>1$ in all the samples irrespective of the six sites and the season-wise analyses (Fig. 8). The translocation (TF) and bioaccumulation (BAF) factors in the selected desert plants were found high when compared to the earlier findings of Conti et al. (2004), Ukpebor et al. (2010) and Reinier et al. (2011). In this study, TF $>1$ suggested a definite pollutant transporting mechanism from the roots to the shoot of plants as described by Fismes et al. (2002), Yu-Hong et al. (2010) and Takanori and Naoko (2012). The TF values in the present study were found comparatively higher than the TF values observed by the earlier investigators.

BAF was $>1$ in all the samples during winter except with variations of $\mathrm{BAF} \leq 1$ in $C$. gigantean, $T$. terrestris and $P$. oleracea during the summer season. This also
Table 1 Season-wise ANOVA tests between trace metals concentrations in particulates, desert plants and soil from six Kuwait sampling sites

\begin{tabular}{|c|c|c|c|c|c|c|}
\hline Source-variation & SS & $d f$ & $F$ & $P$ value & $F$ ratio & Significance \\
\hline \multicolumn{7}{|c|}{ A. Site-wise and season-wise trace metals in $\mathrm{PM}_{10}$ versus metals-wise analysis } \\
\hline $\mathrm{PM}_{10}(\mathrm{~S}, \mathrm{~W})$ & 1082.76 & 11 & 2.18 & 0.02 & 1.90 & $*$ \\
\hline Trace metals & 43321.15 & 8 & 120.04 & $<0.0001$ & 2.05 & * \\
\hline Error & 3969.78 & 88 & & & & \\
\hline Total & 48373.70 & 107 & & & & \\
\hline \multicolumn{7}{|c|}{ B. Site-wise and season-wise trace metals in $\mathrm{PM}_{2.5}$ versus metals-wise analysis } \\
\hline $\mathrm{PM}_{2.5}(\mathrm{~S}, \mathrm{~W})$ & 951.80 & 11 & 2.25 & 0.02 & 1.90 & $*$ \\
\hline Trace metals & 34946.55 & 8 & 113.64 & $<0.0001$ & 2.05 & $*$ \\
\hline Error & 3382.61 & 88 & & & & \\
\hline Total & 39280.97 & 107 & & & & \\
\hline \multicolumn{7}{|c|}{ C. Site-wise and season-wise trace metals in $\mathrm{PM}_{1.0}$ versus metals-wise analysis } \\
\hline $\mathrm{PM}_{1.0}(\mathrm{~S}, \mathrm{~W})$ & 602.93 & 11 & 2.23 & 0.018 & 1.90 & $*$ \\
\hline Trace metals & 23349.05 & 8 & 119.20 & $<0.0001$ & 2.05 & $*$ \\
\hline Error & 2154.563 & 88 & & & & \\
\hline Total & 26106.55 & 107 & & & & \\
\hline \multicolumn{7}{|c|}{ D. Site-wise and season-wise trace metals in aerial parts of the desert plants versus soil analysis } \\
\hline G1-G6 (S,W), soil & 576.12 & 13 & 46.53 & $<0.0001$ & 1.87 & $*$ \\
\hline Desert plants & 955.75 & 5 & 200.71 & $<0.0001$ & 2.35 & $*$ \\
\hline Error & 61.90 & 65 & & & & \\
\hline Total & 1593.77 & 83 & & & & \\
\hline \multicolumn{7}{|c|}{ E. Site-wise and season-wise trace metals in roots of the desert plants versus soil analysis } \\
\hline G1-G6 (S,W), soil & 352.35 & 13 & 17.30 & $<0.0001$ & 1.87 & $*$ \\
\hline Desert plants & 575.86 & 5 & 73.55 & $<0.0001$ & 2.35 & $*$ \\
\hline Error & 101.77 & 65 & & & & \\
\hline Total & 1030.00 & 83 & & & & \\
\hline
\end{tabular}

G1-G6 sites, $S$ summer, $W$ winter, $S S$ sum of squares, $d f$ degree of freedom, $F$ calculated value, $F$ ratio: table value

* Significant; ** insignificant 
indicated the accumulation and non-utility of nonessential trace metals such as $\mathrm{Hg}$, As, Se and $\mathrm{Cr}$ in the aerial plant parts above the ground level (BAF-AGL). Comparatively, $\mathrm{BAF}$ in the aerial parts of the plants (BAF-AGL) was higher than the $\mathrm{BAF}$ in their roots found below the ground level (BAF-BGL) (Fig. 8). BAF $<1$ in T. terrestris, R. vesicarius and $P$. oleracea during summer attributes to the absorption and assimilation of essential metals- $\mathrm{Fe}, \mathrm{Mg}$, $\mathrm{Cd}$ and Mo from their roots (BAF-BGL) of these plants
(Fig. 8). Conti et al. (2004), Youn-Joo (2004) and, Ukpebor et al. (2010) indicated the accumulation of pollutants through the plant leaves during the photosynthetic process than the stem and root that facilitated the absorption and transportation of water and nutrients. ANOVA tests showed significant differences between the metals-wise, season-wise and sites-wise variations of trace metals and the three particulate sizes, soil, desert plants besides their significance to TF, BAF and ATPI values (Tables 1,2).
Table 2 Season-wise ANOVA tests between TF, BAF and APTI from six Kuwait sampling sites

\begin{tabular}{|c|c|c|c|c|c|c|}
\hline Source-variation & SS & $d f$ & $F$ & $P$ value & $F$ ratio & Significance \\
\hline \multicolumn{7}{|c|}{ A. Season-wise TF of desert plants versus metals-wise analysis } \\
\hline Desert plants & 0.022 & 11 & 2.93 & 0.002 & 1.89 & $*$ \\
\hline Trace metals & 0.158 & 8 & 28.69 & $<0.001$ & 2.04 & $*$ \\
\hline Error & 0.060 & 88 & & & & \\
\hline Total & 0.241 & 107 & & & & \\
\hline \multicolumn{7}{|c|}{ B. Season-wise TF of desert plants versus site-wise analysis } \\
\hline Desert plants & 0.918 & 11 & 10.28 & $<0.001$ & 1.96 & $*$ \\
\hline Sites & 0.104 & 5 & 2.57 & 0.036 & 2.38 & $*$ \\
\hline Error & 1.470 & 55 & & & & \\
\hline Total & & 71 & & & & \\
\hline \multicolumn{7}{|c|}{ C. Season-wise BAF in aerial plant parts versus metals-wise analysis } \\
\hline Desert plants & 10.62 & 11 & 8.88 & $<0.001$ & 1.89 & * \\
\hline Trace metals & 18.50 & 8 & 21.29 & $<0.001$ & 2.04 & * \\
\hline Error & 9.55 & 88 & & & & \\
\hline Total & 38.68 & 107 & & & & \\
\hline \multicolumn{7}{|c|}{ D. Season-wise BAF in plant roots versus metals-wise analysis } \\
\hline Desert plants & 10.63 & 11 & 9.75 & $<0.001$ & 1.89 & $*$ \\
\hline Trace metals & 18.14 & 8 & 22.88 & $<0.001$ & 2.04 & * \\
\hline Error & 8.72 & 88 & & & & \\
\hline Total & 37.51 & 107 & & & & \\
\hline \multicolumn{7}{|c|}{ E. Season-wise trace metals BAF in desert plants versus site-wise analysis } \\
\hline Desert plants & 1.031 & 11 & 59.89 & $<0.001$ & 1.96 & * \\
\hline Sites & 0.002 & 5 & 0.36 & 0.867 & 2.38 & $* *$ \\
\hline Error & 0.08 & 55 & & & & \\
\hline Total & 1.12 & 71 & & & & \\
\hline \multicolumn{7}{|c|}{ F. Season-wise APTI of desert plants versus site-wise analysis } \\
\hline Desert plants & 24.79 & 11 & 17.51 & $<0.001$ & 1.96 & $*$ \\
\hline Sites & 48.98 & 5 & 76.13 & $<0.001$ & 2.38 & * \\
\hline Error & 7.077 & 55 & & & & \\
\hline Total & 80.85 & 71 & & & & \\
\hline \multicolumn{7}{|c|}{ G. Season-wise TF, BAF, APTI versus site-wise analysis } \\
\hline Sites & 2885.96 & 17 & 1251.50 & $<0.001$ & 1.67 & $*$ \\
\hline Desert plants & 8.987 & 11 & 6.02 & $<0.001$ & 1.84 & $*$ \\
\hline Error & 25.36 & 187 & & & & \\
\hline Total & 2920.32 & 215 & & & & \\
\hline
\end{tabular}

G1-G6 site, $S$ summer, $W$ winter, $S S$ sum of squares, $d f$ degree of freedom, $F$ calculated value, $F$ ratio: table value, $T F$ translocation factor, $B A F$ bioaccumulation factor, $A P T I$ air pollution tolerance index

* Significant; ** insignificant 


\section{Conclusion}

This study revealed a specific pattern of particulates dispersion route and the concentrations of trace metals in particulates collected from the six Kuwait Governorate sites during the summer and winter seasons. This dispersion of particulates was found significance to the absorption and accumulation of trace metals in desert plants. These desert plants are an excellent air pollution biomarker, using the quantitative and qualitative indices. The present study enables the landscape designers to distinguish sensitive and tolerant plants, recommend the cultivation of suitable desert plants to mitigate pollution and undertake an ecological conservation management plan.

Acknowledgments Appreciation expressed to the Kuwait Foundation for the Advancement of Sciences (KFAS) for their invaluable financial support to the projects Grants No. KFAS-2012-1401-04 and KFAS-2013-1401-02. Acknowledgment extended to the Research Administration, Kuwait University, for their technical support. We thank Dr. K.T. Mathews, Curator, Department of Biological Sciences, Kuwait University, for identifying the desert plants.

\section{Compliance with ethical standards}

Conflict of interest The authors have no conflict of interest in the technicalities of this investigation.

\section{References}

Abida B, Harikrishna S (2010) Evaluation of some tree species to absorb air pollutants in three industrial locations of South Bengaluru India. E-J Chem 7(S1):51-56. Academic Journal 57956745

Agbaire PO (2009) Air pollution tolerance indices (APTI) of some plants around Erhoike-Kokori oil exploration site of Delta state, Nigeria. Int J Phys Sci 4(6):366-368. ISSN: 1992-1950

Bader Al-Azmi N, Nassehi V, Khan AR (2008) Comparative assessment of ambient air quality in Rabia area for the years 2001 and 2004 in the State of Kuwait. Am J Environ Sci 4(1):50-62. doi:10.3844/ajessp.2008.50.62

Baker AJM, Brooks RR (1989) Terrestrial higher plants which hyper accumulate metallic elements-a review of their distribution, ecology and phytochemistry. Biorecovery 1:81-126. ISBNISSN: 0269-7572

Briggs GA (1979) Some recent analyses of plume rise observations. In: Proceedings of the second international clean air congress, Academic Press, New York

Brown KW, Bouhamra W, Lamoureux DP, Evans JS, Koutrakis P (2008) Characterization of particulate matter for three sites in Kuwait. J Air Waste Manag Assoc 58(8):994-1003

Bu-Olayan AH, Thomas BV (2014) Assessment of the ultra-mercury levels in selected desert plants. Int $\mathrm{J}$ Environ Sci Technol 11(5):1413-1420. doi:10.1007/s13762-013-0324-y

Cheng FY, Burkey KO, Robinson JM, Booker FL (2007) Leaf extracellular environment ascorbate in relation to $\mathrm{O}_{3}$ tolerance of two soya bean cultivars. Environ Pollut 150:355-362. doi:10. 1016/j.envpol.2007.01.022

Conti ME, Tudino M, Stripeikis J, Cecchetti G (2004) Heavy metal accumulation in the Lichen Everina prunastri transplanted at urban, rural and industrial sites in Central Italy. J Atmos Chem 49(1-3):83-94. ISSN: 0167-7764

Cyren MR, Sanghamitra M, Maria DG, Jose RPV, Jorge LGT (2011) Interaction of nanoparticles with edible plants and their possible implications in the food chain. J Agric Food Chem 59(8):3485-3498. doi:10.1021/jf104517j

Dohmen GP, Loppers A, Langebartels C (1990) Biochemical response of Norway Spruce (Picea Abies (L) Karst) towards 14-month exposure to ozone and acid mist, effect on amino acid, glutathione and polyamine titers. Environ Pollut 64:375-383. doi:10.1016/0269-7491(90)90059-L

Fismes J, Perrin-Ganier C, Empereur-Bissonnet P, Morel JL (2002) Soil-to-root transfer and translocation of polycyclic aromatic hydrocarbons by vegetables grown on industrial contaminated soils. J Environ Qual 31:1649-1656. doi:10.2134/jeq2002.1649

Joshi P, Swami A (2007) Physiological responses of some tree species under roadsides automobile pollution stress around city of Haridwar, India. The Environmentalists 27:365-374. doi:10. 1007/s10669-007-9049-0

Jyothi SJ, Jaya DS (2010) Evaluation of air pollution tolerance index of selected plant species along roadsides in Thiruvanthapuram, Kerala. J Environ Biol 31:379-386

Keane B, Collier MH, Shann JR, Rogstad SH (2001) Metal contents of dandelion (Taraxzcum officinale) leaves in relation to soil contamination and airborne particulate matter. Sci Total Environ 281:63-78. doi:10.1016/S0048-9697(01)00836-1

Liu Y, Ding H (2008) Variation in air pollution tolerance index of plants near a steel factory implication for landscape-plant species selection for industrial areas. WSEAS Trans Environ Dev 4:24-32. ISSN: 1790-5079

Ma LQ, Komar KM, Tu C, Zhang W, Cai Y, Kenelly ED (2001) A fern that hyper accumulates arsenic. Nature 409:579-582. doi:10.1038/35054664

Ninave SY, Chaudri PR, Gajghate DG, Tarar JL (2001) Foliar biochemical features of plants as indicators of air pollution. Bull Environ Contam Toxicol 67:133-140. doi:10.1007/s001280101

Pasquill F (1976) Atmospheric dispersion parameters in Gaussian Plume Modelling. Part II: possible requirements for change in the turner workbook values. EPA-600/4-76-030b, USEPA, research triangle park, North Carolina, 27711

Press W, Flannery B, Teukolsky S, Vetterling W (1986) Numerical recipes. Cambridge University Press, New York

Rahimi A, Hosseini MS, Pooryoosef M, Fateh I (2010) Variation of leaf water potential, relative water content and SPAD under gradual drought stress and stress recovery in two medicinal species of Plantago ovata and P. psyllium. J Plant Ecophysiol 2(2):53-60. ISSN: 2008-7861

Reem SE, John GZ, El-Rifaia MA, Hisham ME (2010) An assessment of the air pollution data from two monitoring stations in Kuwait. Toxicol Environ Chem 92(4):655-668. doi:10.1080/ 02772240903008609

Reinier MM, Martina GV, Willie JGMP (2011) Metals and metalloids in terrestrial systems: bioaccumulation, bio-magnification and subsequent adverse effects (Chapter 3) In: Ecological Impacts toxic chemistry. Bentham Science Publishers Ltd, pp 43-62. eISBN: 978-1-60805-121-2

Seyyednejad SM, Koochak H (2013) Some morphological and biochemical responses due to industrial air pollution in Prosopis juliflora (Swartz) DC plant. J Biol Sci 8(18):1968-1974. doi:10. 5897/AJAR10.652

Seyyednejad SM, Majdian K, Koochak H, Nikeneland M (2011) Air pollution tolerance indices of some plants around industrial zone in South of Iran. Asian J Biol Sci 4(3):300-305. doi:10.3923/ ajbs.2011.300.305

Smirnoff N (1996) The functions and metabolism of ascorbic acid in plants. Ann Bot 78(6):661-669. doi:10.1006/anbo.1996.0175 
Takanori K, Naoko KN (2012) Iron uptake, translocation, and regulation in higher plants. Annu Rev Plant Biol 63:131-152. doi:10.1146/annurev-arplant-042811-105522

Ukpebor EE, Ukpebor JE, Aigbokhan E, Goji I, Onojeghuo AO, Okonkwo AC (2010) Delonix regia and Casuarina equisetifolia as passive bio monitors and as bio accumulators of atmospheric trace metals. J Environ Sci (China) 22(7):1073-1079. doi:10. 1016/S1001-0742(09)60219-9

USEPA (1999) Compendium of methods (IO-3.5) for the determination of inorganic compounds in ambient air (EPA/625/R-96/ 010a)

Wang X, Shan X, Zhang S, Wen B (2004) A model for evaluation of the phyto availability of trace elements to vegetables under the field conditions. Chemos 55:811-822. doi:10.1016/j. chemosphere.2003.12.003
Yoon J, Cao X, Zhou Q, Ma LQ (2006) Accumulation of Pb, Cu, and $\mathrm{Zn}$ in native plants growing on a contaminated Florida site. Sci Total Environ 368(2-3):456-464. doi:10.1016/j.scitotenv2006. 01.016

Youn-Joo A (2004) Soil ecotoxicity assessment using cadmium sensitive plants. Environ Pollut 127(1):21-26. doi:10.1016/ S0269-7491(03)00263-X

Yu-Hong S, McGrath SP, Zhao FJ (2010) Rice is more efficient in arsenite uptake and translocation than wheat and barley. Plant Soil 328(1-2):27-34. doi:10.1007/s11104-009-0074-2

Zhuang P, Yang QW, Wang HB, Shu WS (2007) Phyto-extraction of heavy metals by eight plant species in the field. Water Air Soil Pollut 184:235-242. doi:10.1007/s11270-007-9412-2 